\title{
Gender, culture and the politics of identity in the public realm
}

Andrea Baumeister

University of Stirling, UK

\begin{abstract}
Although recent debates surrounding the relationship between commitments to gender equality and cultural justice have given a renewed impetus to feminist critiques of liberal conceptions of the public realm, prominent interventions by Martha Nussbaum and Monique Deveaux have continued to affirm one of two long-standing, yet controversial, feminist strategies for reconceptualising the public realm. While Nussbaum's expansive notion of the public realm ultimately rests on a substantive conception of the good that cannot be readily reconciled with the aims of non-liberal feminist movements, Deveaux's democracy approach struggles to define conditions for democratic participation that are substantive enough to safeguard the central goals of her feminist project and yet respect the diversity of women's actual values and cultural attachments. These difficulties point towards the need for a more sophisticated understanding of the interaction between the capacity for agency in the wider social and personal sphere and effective citizenship in the public realm. Although a purely procedural account of democratic deliberation avoids the dangers of false universalism, it can only secure effective citizenship for women if some of the most serious structural inequalities that confront women are addressed. While such an approach falls well short of the demands associated with models such as Nussbaum's expanded public realm, it none the less places significant limits on the scope of democratic deliberation.
\end{abstract}

Keywords: gender equality; group rights; political liberalism; democratic deliberation; Nussbaum; Deveaux 
Recent debates surrounding the relationship between a commitment to gender justice and demands for group rights for religious, ethnic and cultural minorities have given a renewed impetus to feminist critiques of liberal conceptions of the public realm. While questions of cultural justice have played a prominent role in liberal political theory for some considerable time, theorists have been slow to consider the impact of group rights upon gender equality. Indeed, some have explicitly invoked the notion of individual and group autonomy to argue that out of respect for cultural diversity the state should not intervene in the private sphere of family, religious and personal life. ${ }^{1}$ From a feminist perspective such responses are deeply troubling. As feminist scholars have long argued, if women are to achieve equal citizenship, power relations in the private sphere must be subject to critical analysis and political intervention, and gender bias in the public sphere must be challenged (Arneil, 2007). At the same time there has been an increasing realisation among feminists that such a critique must be sensitive to women's actual choices, values and cultural attachments. Although established cultural and religious practices are frequently at odds with a liberal conception of gender equality, many women strongly identify with the traditional way of life of their community. ${ }^{2}$ Indeed, rather than reject their cultural heritage, many indigenous feminist movements reside within their cultural traditions.

Although feminists have been careful to acknowledge the impact of such cultural attachments for feminist critiques of the liberal public realm, recent interventions by Martha Nussbaum (1999) and Monique Deveaux (2006) have continued to affirm one of two long-standing, yet controversial, feminist strategies for reconceptualising the public realm. Although Nussbaum stresses that a feminist defence of gender equality should be grounded in a form of political liberalism that acknowledges a plurality of 
comprehensive doctrines of the good, unlike Rawls, Nussbaum champions an expansive conception of the public realm, favouring wide-ranging intervention in the family and women's position in society to promote gender equality. Nussbaum's approach here echoes the well-established feminist strategy, championed most prominently by Susan Okin (1994), of extending liberal principles to what is traditionally perceived as the private sphere of family, marriage and sexuality. While advocates of this approach stress the significance for women of traditional liberal values such as autonomy, equality and individual liberty, they reject the narrow conception of the public realm and the sharp public/private distinction that characterise the liberal tradition, pointing to the impact unequal power relations in the private realm have upon women's capacity for agency and effective citizenship. Thus, while Nussbaum acknowledges that respect for cultural and religious diversity entails the recognition of a private sphere free from state intervention, she argues that religious and cultural norms that threaten to undermine women's basic human rights and their capacity to develop core human capabilities must be challenged. Deveaux, in contrast, advocates a democracy approach that seeks to re-evaluate the distinction between public and private through the creation of new spaces for democratic activity that empower minority women and facilitate critical debate about established cultural norms and practices. On this account, successful democratic deliberation must engage with participants' strategic interests and must respect their actual choices and preferences, even if these entail non-liberal outcomes. For Deveaux such democratic activity is not confined to formal political processes, but also entails acts of cultural dissent, subversion and reinvention in what has traditionally been regarded by liberal theorists as the private realm. This approach reflects the well-established concerns of feminists such as Iris Marion Young (1990) who have sought to promote a 'politics of 
difference' that brings the values, experiences and voices of those traditionally confined to the private sphere into the realm of democratic politics. While advocates of the first strategy seek to expand the scope of liberal values, proponents of this approach argue that the exclusion of particularity from the public sphere associated with the liberal emphasis on formal equality and impartiality gives rise to a conception of citizenship that privileges dominant perspectives at the expenses of groups such as women who have been historically marginalised. ${ }^{3}$

These two strategies have tended to reflect more general epistemological controversies within feminism concerning self, subject and subjectivity. While feminists attracted to the democratisation route have tended to emphasise the 'situated, specific, historically embodied condition of the female subject' and the impact of 'socio-cultural identities based on ethnicity, religion, sexuality, class and colour' upon agents' interests (Dietz 2003:409), advocates of the 'expanded public realm' strategy have defended the idea of a 'generalisable, identifiable and collectively shared experience of womanhood' (Okin 1994:4). The paper argues that the ensuing fierce debate among feminists regarding the dangers of false universalism on the one hand and the fragmentation of the feminist project on the other, continues to cast a shadow over contemporary feminist critiques of dominant discourses regarding gender, culture and the public realm. Although Nussbaum aims to develop a difference sensitive feminism that avoids the dangers of false universalism, her expansive notion of the public realm ultimately rests on a substantive conception of the good that cannot be readily reconciled with the aims of non-liberal feminist movements. Yet, while Deveaux’s democracy approach promises to enable the diverse voices of women to be heard, Deveaux struggles to define conditions for 
democratic participation that are substantive enough to safeguard the central goals of her feminist project and yet respect the diversity of women's actual choices, values and cultural attachments. These difficulties point to the need for a more sophisticated analysis of the complex interaction between the capacity for agency in the wider social and personal sphere and effective citizenship in the public realm. While a purely procedural account of democratic deliberation is well placed to ensure that cultural minorities are able to bring their values and norms to bear in the public realm, it can only secure effective citizenship for vulnerable group members such as women if some of the most serious structural inequalities in the wider social sphere, such as economic deprivation and lack of education, are addressed. While such an approach falls well short of the demands associated with models such as Nussbaum's expansive public realm, it none the less places significant limits on the scope of democratic deliberation.

\section{Political Liberalism and the Expanded Public Sphere: Nussbaum's Capabilities}

\section{Approach}

In Sex and Social Justice Martha Nussbaum (1999b) explicitly seeks to redress the relationship between feminism and liberalism. While feminists have typically been critical of liberalism's emphasis on individualism, formal equality and abstract reason, Nussbaum believes that properly conceived and consistently implemented, liberalism provides the basis for a robust defence of gender equality as a central human right. For Nussbaum, not only does the impartiality implied by a liberal notion of a common humanity offer a powerful challenge to often deeply entrenched discrimination against women, but the liberal emphasis on self-sufficiency as economic independence constitutes also an important goal for many women, who still lack sufficient resources 
to care for themselves. Furthermore, the primacy of the individual has much to offer to women, whose well-being is only too frequently sacrificed or subordinated to the interests of family or the wider community and who have 'too rarely been treated as ends in themselves, and too frequently treated as means to the ends of others'(Nussbaum 1999: 63). Finally, given the patriarchal nature of most societies, women have good grounds to distrust habit and tradition. After all 'where the voice of tradition speaks, that voice is most often male' (Nussbaum 1999b: 79). Thus, far from rejecting the liberal emphasis on reason, women have great need of this capacity.

While for Nussbaum the core liberal values of personhood, autonomy, dignity and self-respect offer the most effective tools for securing equality for women world wide, she is nonetheless keenly aware of the difficulties that cultural diversity and demands for cultural justice pose for any liberal universalist project. Many adherents to nonliberal life-styles and conceptions of the good remain deeply committed to their way of life and continue to uphold traditions and customs, many of which cannot be easily reconciled with the norm of gender equality. This poses a complex dilemma. After all, it is difficult to see how one could be said to respect the bearers of such conceptions of the good, without at the same time respecting their choice to continue to uphold their traditional way of life. In the face of these difficulties, Nussbaum argues that a feminist defence of gender equality should be grounded in a form of political liberalism which acknowledges the plurality of comprehensive doctrines of the good. Although political liberals insist that a 'nonautonomous life should not be thrust upon someone by luck of birth', they nonetheless respect that reasonable citizens may pursue such lives, 'given a background of liberty and opportunity' (Nussbaum 1999a:110). While such an approach will require adherence to non-liberal 
perspectives to acknowledge the equality of women as citizens, it does not demand that non-liberal perspectives endorse women's equality as a comprehensive moral value. Thus, Nussbaum claims, her political liberalism rests upon a thin universalism that allows for reasonable pluralism.

Central to Nussbaum's project is her capabilities approach, which seeks to identify activities characteristically performed by humans, which are so central that they are definitive of a life that is truly human. That is to say they are functions 'without which (meaning without the availability of which) we would regard a life as not, or not fully, human’ (Nussbaum 1999b: 39). Here Nussbaum stresses that her approach does not aim to merely secure the necessities for bare survival, but seeks to identify the capacities required for full human functioning. In Sex and Social Justice she identifies the following central human functional capabilities: A normal life span, bodily health and physical integrity (clauses 1-3); emotional, affective, social and mental development (clauses 4, 5, 7 and 9); the ability to engage in critical reflection about the planning of one's own life (clause 6); the ability to live with concern for and in relation to animals, plants and the environment (clause 8) and control over one's own environment, both in terms of political participation and control over material goods (clause 10). ${ }^{4}$ While some of these central capabilities, such as political liberties, can be fully guaranteed by society, Nussbaum acknowledges that others, like good health, may involve an element of chance. These items on the list are therefore best viewed as political goals that provide a useful benchmark for aspirations and comparisons between the relative well-being of men and women. 
According to Nussbaum, this list of central human capabilities is neither ahistorical nor a priori, but reflects 'empirical findings of a broad and ongoing cross-cultural inquiry’ (Nussbaum 1999b: 40). Thus for Nussbaum these central capabilities are akin to Rawls’ primary goods. They are

'something that people from many different traditions, with many different fuller conceptions of the good, can agree on as the necessary basis for pursuing their good life. That is why the list is deliberately rather general. Each of its components can be more concretely specified in accordance with one's origin, religious beliefs, or tastes. In that sense, the consensus that it hopes to evoke has many of the features of the overlapping consensus described by Rawls'. (Nussbaum 1999b:40)

However Nussbaum’s approach differs from Rawls’ political liberalism in at least two important respects. Whereas Rawls develops his political liberalism within the context of modern liberal societies, Nussbaum regards her list of capabilities as universally applicable. Furthermore, while Rawls’ political liberalism only applies to the basic structure of society in the political sphere, Nussbaum favours 'wide-ranging intervention by the state and other bodies to change the family and women's place in society and in turn the comprehensive doctrines that underpin family structures' (Enslin 2003:83). Thus, while Nussbaum recognises that respect for cultural and religious diversity entails the recognition of a private sphere free from state intervention, her conception of political liberalism rests on a much more expansive conception of the public realm than that advocated by writers such as Rawls. For Nussbaum, if liberalism is to fulfil its promise to secure for women autonomy, dignity, and self-respect, norms governing family, religious or cultural life that threaten to undermine women's basic human rights and their capacity to develop core human capabilities must be challenged. ${ }^{5}$ 
Yet, while the liberal emphasis on impartiality and formal equality undoubtedly has provided women with an important weapon in their struggle for political inclusion (Phillips, 1993), the strategy of extending these values to aspects of family, religious and cultural life has given cause for considerable disquiet among feminists. Most notably it has given rise to the worry that such an approach rests on a false universalism that unduly privileges liberal values and fails to pay sufficient attention to women's actual choices, values and commitments. ${ }^{6}$ Although Nussbaum claims her thin universalism is attentive to the claims of difference and diversity and thus avoids these long-standing concerns, the difficulties associated with her expanded conception of the public realm raise doubts about whether she succeeds in her aims. Nussbaum's discussion of freedom of religion provides a good illustration of the problems she faces in this regard. For Nussbaum the ability to search for the good in a religious way constitutes one of the liberties most deserving of protection. Thus, although all citizens must acknowledge women's equality in the public realm, as a political liberal Nussbaum acknowledges that respect for citizens' different comprehensive conceptions of the good sets limits to the degree to which the state can legitimately intervene in religious and cultural practices. Hence, where laws designed to ensure non-discrimination on the grounds of gender impact upon the very core of religious practices and thus place a substantial burden on the free exercise of religion, the protection of religious liberty may at times provide a compelling ground for an exemption, 'as long as the law in question is narrowly tailored to protect that interest' (Nussbaum 1999b:111). Thus, religious groups may, for instance, be granted an exemption from sex discrimination law in the appointment of priests. However, 'no system of religious laws should be permitted to interfere with the basic human rights of citizens' (Nussbaum 1999b:103). Consequently, with regard to matters that fall 
within the public sphere, which on Nussbaum's account includes the family, the upbringing of children, and the status of women in society in general, the state has good reasons to intervene in religious practices that violate the norm of gender equality. Thus, for example, the state should not uphold any religious, personal or family laws that discriminate against women. Furthermore, a religious leader who employs speech in the public realm to deny women's equal humanity, be it to justify marital rape or to attack contraception, 'should be strongly criticised as a subverter of the constitution’ (Nussbaum 1999b:114). Finally, while parents may have a legitimate interest in raising their children within their religion, the state must ensure that all children are able fully to develop their capabilities. Therefore girls must be given an equal education that equips them for employment and citizenship and be made aware of the public commitment to the norm of gender equality.

As these examples suggest, on Nussbaum's expansive reading of the public sphere, the demand to respect women's equality as citizens will place considerable burdens on non-liberal perspectives. For instance, while Islamic law is rooted in a patriarchal view of society and advocates different rights for men and women, for many Muslims adherence to Islamic personal and family law is a 'quintessential sign of loyalty to Islam and thus for many Islamic groups constitutes the core of Islamic identity' (Loenen 2002:426). Yet, such an understanding of what comprises the core of a religious identity cannot be readily reconciled with Nussbaum's expansive view of the public sphere. After all on Nussbaum’s account personal and family law fall within the public realm and thus cannot be exempt from the norm of gender equality. Similarly, Nussbaum's view of what should be viewed as an attack upon women's constitutional right to equality does not sit easily with the commitment of the Catholic 
Church to publicly oppose and criticise contraception. Indeed on Nussbaum's account anyone who publicly endorsed the view that life begins at conception would have to be classed a 'subverter of the constitution'. As these examples indicate, ultimately Nussbaum's expansive account of the public realm entails quite a substantive conception of the good. Such a thick conception of the good cannot be readily reconciled with her claim to advance a form of thin universalism.

More troubling still from a feminist perspective, the thick conception of the good that underpins Nussbaum's conception of an expanded public sphere is not well suited to support the aims and aspirations of many non-liberal feminist movements. While Nussbaum (1999b:66) quite rightly points to many examples of women around the world who are 'using the language of liberalism' in their struggle for gender equality, at least some feminist movements do not endorse the liberal conception of gender equality, but instead situate their demands for equality within the context of their traditional culture, religion or class. Thus, for example, the feminism of many Muslim feminists is firmly rooted in Islam, giving rise to a fight for liberation in a religious context. Rather than reject the legitimacy of traditional Islamic personal and family law, these feminists have thought to re-interpret existing law to promote greater equality via an appeal to alternative readings of the Qur'an or by pointing to inconsistencies in current practices (Eissa 1999; Moosa 1995; Fazaeli 2007). In this context Muslim feminists typically stress that the aim of such a reassessment is to offer a more authentic interpretation of the Islamic tradition.

Although Nussbaum (1999b: 70/71) believes that such anti-liberal feminists are unwise to 'jettison the liberal account of human essence in favour of an account that 
gives more centrality to "accidental" features such as religion or class or even gender', she stresses that her type of political liberalism 'strives to leave space for these other identities'. Yet, given the rather substantive nature of Nussbaum's liberal universalism, her claim to be able to accommodate a wide variety of non-liberal feminisms is at best problematic. For example, Nussbaum's view of what respect for women's equality as citizens entails cannot be easily reconciled with the conception of the political realm and its relationship to Islam inherent in the position of Muslim feminists committed to Islamic personal and family law. Furthermore, the emphasis upon individual autonomy and critical reason in clause 6 of Nussbaum's list of core human capabilities will leave many feminists who have consistently attacked this typically liberal conception of identity with a considerable sense of unease. ${ }^{7}$ While these tensions between diverse feminisms arguably constitute a real dilemma for any feminist who seeks to ground a defence of gender equality in a liberal paradigm, it is a problem that Nussbaum does not address. Indeed, although Nussbaum (1999b:9) claims that her approach 'lets the voices of many women speak', one of the most striking features of Sex and Social Justice is its failure to systematically engage with the work of non-liberal feminists, whose conceptions of gender equality challenge her liberal feminist paradigm. ${ }^{8}$ From a feminist perspective this oversight is rather telling. While feminism has been sensitive to the dangers of uncritically endorsing cultural norms, it has also been keenly aware of the perils of presenting culture specific norms as universal principles. Indeed, historically much of the feminist critique of liberalism has been fuelled by worries regarding misleading universalist claims. In her quest to develop a universal defence of gender equality, Nussbaum underestimates the extent to which views of what constitutes gender equality are shaped by cultural factors and 
thus fails to allay long-standing feminist concerns surrounding attempts to promote gender equality by expanding the scope of the liberal public realm.

\section{Diversity within the Public Realm: Deveaux’s Democratisation Approach}

In the light of the difficulties that surround Nussbaum's strategy, feminists may well be attracted to approaches, such as Deveaux's (2006) attempt to re-evaluate the distinction between public and private through the creation of new spaces for democratic activity that empower minority women and facilitate critical debate about established cultural norms and practices. In contrast to Nussbaum's normative approach, which characterises tensions between gender equality and cultural justice as first and foremost a clash of values, Deveaux argues that such disputes most often reflect disruptions in social power relations and hierarchies and are thus best analysed in term of power and democratic practice. Indeed tensions between liberal norms and many of the cultural practices that have given rise to concern among feminists expose not just intercultural disputes, but often also highlight intracultural disagreements over the interpretation, meaning and legitimacy of particular norms. Such conflicts are often strategic or political in character reflecting interests and power relations both within the community and between the community and the wider society. For example, in recent years there has been considerable debate within Jewish and Muslim communities regarding the origin, nature and interpretation of the communities’ personal and family law. ${ }^{9}$

Deveaux argues that conflicts about cultural practices that are at odds with the norm of gender equality are best addressed through deliberative forums that bring together a cross section of the community, including community leaders, representatives from 
women's groups, representatives from groups with special expertise, such as legal reform groups, and government policy makers. Her model of democratic deliberation here is explicitly political and conceives of deliberation not as moral argumentation aimed at normative consensus, but as engaged with citizens' strategic interests and needs, and focused on practical concerns and concrete consequences. In stark contrast to Nussbaum's tendency to condemn those who publicly challenge women's equal humanity as ‘subverters of the constitution', Deveaux (2006:220) explicitly rejects the notion that the interests of vulnerable group members such as women are best protected by preventing 'the introduction of normatively unreasonable or unjust claims in political dialogue'. Such an approach merely encourages participants to present strategic interests as moral arguments, and interest based concerns as issues of cultural identity. Not only do such moves make disputes appear more intractable, they often also camouflage power relations 'with the result that some individuals are left more vulnerable or powerless’ (Deveaux, 2007: 101). Rather than exclude strategic interests, deliberation should encourage participants to give 'frank and concrete reasons in support of particular customs and proposals for or against change' (Deveaux 2005:349). According to Deveaux, the ensuing negotiations, bargaining and compromises encourage critical reflection upon the validity of the participants' interests. In this context 'those that simply seek to maintain control over vulnerable members of their community ... will be hard pressed to disguise their motive or find a legitimate justification for it that cannot be revealed as cynical window-dressing' (Deveaux 2005:350).

To ensure that such political deliberation does not simply shore up the advantages of the powerful a number of conditions must be met. Firstly, deliberation about contested 
cultural practices should 'take place against the background of a liberal democratic state that protects fundamental individual rights and freedoms', and which secures the 'moral minimum' by prohibiting customs that cause serious physical harm and require outright coercion (Deveaux, 2006:94). Furthermore, in addition to the norm of democratic legitimacy, which demands that all affected by decisions should be consulted, political deliberation should be bound by three further principles: nondomination, political equality and revisability. While the principle of non-domination aims to ensure that traditionally marginalised group members cannot be silenced though pressure tactics or overt oppression, the principle of political equality seeks to guarantee 'the presence of real opportunities for all citizens to participate in debate and decision-making' (Deveaux 2005:350). This not only requires that such opportunities are in principle available, but also entails trying to prevent “"extrapolitical and endogenous forms of influence, such as power, wealth and preexisting social inequalities” from impacting deliberation and its outcome’ (Deveaux 2005:350). Finally, the principle of revisability stipulates that it should always be possible to revisit decisions at a later date. This implies that outcomes of deliberation are only just if they do not undermine the 'future ability of citizens to deliberate on these or other issues if and when they are revisited' (Deveaux 2006: 116/7).

Applying the principle of political equality to cultural conflicts clearly poses a complex and difficult challenge, given that who counts as a group member is at times contested and that 'who can participate in political life is, for many culturally determined' (Deveaux 2005:351). The latter difficulty can pose a particular obstacle to the inclusion of marginalised group members such as women. While Deveaux (2005:351) acknowledges these difficulties, she argues that such problems can be addressed, at least in part, 'though the deliberate expansion of informal sites of social 
and political debate and contestation'. For Deveaux such informal democratic activity extends not just to civil society, but includes social practices and responses to social norms and restrictions. Individual members of groups can and do challenge discriminatory rules or practices within their cultures by protesting to group leaders, 'seeking legal and political support outside of the collective', or by employing informal acts of resistance aimed at reshaping social norms and customs (Deveaux 2006:16). Such informal democratic activity 'can speak volumes about the legitimacy or illegitimacy of roles and customs' and thus needs to be taken into account in assessing the validity of social and cultural practices (Deveaux 2006:118).

As a concrete example of how deliberative processes can give rise to reforms that promote greater gender equality, while respecting traditional non-liberal values and commitments, Deveaux points to the negotiations in the 1990s leading up to the reform of customary marriages in South Africa. Under established customary law as practiced by most blacks in South Africa, women were denied the right to inherit land, enter into contracts, initiate their own divorces, or retain equal custody rights vis-à-vis children in the case of divorce. Since such practices could not be readily reconciled with the equality clause in the Bill of Rights enshrined in the South African constitution, the South African Law Commission set up in 1998 a series of consultations that brought together a cross section of the community, including representatives from legal reform groups and women's associations, Chiefs from the Congress of Traditional Leaders of South Africa (CONTRALESA) and scholars of constitutional and customary law. Despite initial opposition by tribal chiefs, the negotiations provided the basis for considerable reform of traditional customary law, giving rise to the recognition of women's contractual and property rights, securing for women equal guardianship and custody rights in relation to children, and placing 
divorce and custody matters in the hands of family courts. However, the consultation process also highlighted widespread support for the retention of lobolo or bridewealth (although no longer required for the validity of a marriage) and endorsed the continued recognition of polygyny in order to provide legal protection for the interests of women in polygynous marriages.

At first glance Deveaux's emphasis on negotiation and debate, and her preoccupation with practical concerns and consequences, appear to make her approach well suited to the aspirations of indigenous feminist movements such as Muslim and Jewish feminists, who have sought to promote greater gender equality through the reinterpretation of the existing legal traditions surrounding Jewish and Muslim family law. For these feminists the promise of formal and informal democratic forums that will facilitate critical debate and enable reassessments is clearly attractive. However, ultimately, Deveaux’s model remains problematic on at least two counts: (a) Not only is her discussion of the conditions for democratic participation ambiguous, (b) her account of the conditions for agency is not sufficiently robust to ensure that all women acquire the capacities essential for democratic citizenship.

While Deveaux stresses the pragmatic, issue-based nature of her approach, her formulation of the conditions for democratic deliberation is arguably much more substantive and demanding than the South African example would suggest. In her critique of Deveaux, Okin (2005), for example, questions whether the South African marriages case does indeed meet Deveaux's criteria for non-domination and political equality. As Okin notes, the participation of non-elected tribal leaders does not sit well with Deveaux's argument that in order to guarantee political equality extrapolitical forms of influence such as power, wealth and pre-existing social inequalities 
should not be allowed to influence deliberations and outcomes. Furthermore, the resistance by at least some tribal leaders to the very idea that women should play a greater part in decision-making in South African society 'must affect the power dynamic of the process, especially between the women (whom such leaders could hardly have regarded as their political equals) and the leaders (whom quite probably some of the women saw as 'more than equals') (Okin 2005:83). As Okin's concerns highlight, in their current formulation Deveaux’s criteria for democratic participation may well have more far reaching implications then she acknowledges. Not only may the principle of equality entail much more careful attention to who is to act as a representative and how representatives are chosen, but the principle of nondomination may well require precisely the kind of wide-ranging intervention in the family and women's position in society in general favoured by Nussbaum. While critics like Okin may welcome such extensive intervention, it cannot be readily reconciled with Deveaux's aim to offer a procedural account of democratic deliberation that respects the values of participants and engages with their strategic interests. Indeed, it is doubtful whether such a substantive reading would gain the support of traditional cultural and religious minorities. While the rules of democratic deliberation and decision-making undoubtedly impose burdens upon traditional cultural and religious communities, Deveaux (2006:222) stresses that her procedural account would none the less be attractive to such minorities, since it would enable them to maintain 'a degree of self-determination as regards cultural reform' and thus may constitute 'the best available option'. ${ }^{10}$ Yet, if the conditions of democratic participation themselves already entail significant revisions to the very substance of traditions, practices and norms, it is difficult to see why powerful members of communities should be motivated to participate in such processes. Indeed, according 
to Deveaux (2006:219) her procedural account of democratic deliberation implies that 'group members may justly reject the imposition of an a priori norm of equality on the terms and outcomes of political debate'. Yet, on a substantive reading of the conditions of democratic participation it is hard to envisage that the process would generate anything other than predominately liberal outcomes.

In the light of these difficulties Deveaux may well wish to adopt a more minimal reading of the conditions for democratic participation. Her endorsement of the South African case points to a reading of the conditions for democratic participation that emphasises participation and voice and the prevention of overt coercion, but that would not seek to eliminate all extrapolitical and endogenous forms of influence. After all, to insist on eliminating the influence of all extrapolitical factors such as power, wealth and pre-existing social inequalities, risks prescribing an over-idealised and ultimately overly demanding conception of political deliberation, that threatens to impose upon cultural and religious communities conditions that are rarely, if ever, met in democratic deliberations within liberal societies. Yet, while a minimal reading fits well with the notion of a procedural account of democratic deliberation, it offers notably less protection to vulnerable group members such as women. If extrapolitical and endogenous forms of influence cannot be eliminated from formal democratic deliberations, traditionally marginalised group members will need to be confident and robust in defence of their own interests. The extent to which women can successfully protect their interests under such conditions will to a considerable degree depend upon the wider background conditions that shape women's agency and the success or otherwise of informal sites of political debate and contestation that, on Deveaux's model, support the formal deliberative processes. 
While Deveaux is keenly aware that the development of deliberative procedures that do not simply re-inscribe existing power relations requires careful attention to the wider social and political context, she rejects the liberal emphasis upon autonomy as a key criterion for individual agency. For Deveaux (2007:145) an 'emphasis on selfdetermination or capacities for self-definition or authenticity' obscures the benefits individuals may derive from complying with established norms and practices and 'disposes the liberal state towards regulating or even censuring too wide a range of social customs'. For Deveaux (2007:151) customs such as arranged marriage are best conceived not as options that otherwise autonomous individuals choose among a range of alternatives, but as frameworks 'for achieving other things of value, namely marriage, children, tradition, and family and social acceptance'. In the light of this, Deveaux (2007:151) proposes an account of agency that rather than 'insist that central aspects of one's identity must be submitted to significant critical scrutiny', focuses on 'the range of actual and possible individual responses to specific customs and arrangements' and on 'subtler expressions of reflection and action, such as subverting a cultural tradition from the inside'. On this account agency constitutes 'any activity or expression that signals a response to a prevailing social norm, custom, role or arrangement' which reflects or helps to 'secure something that the person has cause to value' (Deveaux 2007:153/157). In this context Deveaux (2006: 124) repeatedly emphasises the indirect ways in which women in traditional communities tend to exercise agency through small decisions such as acts of social transgression, subversion or indirect resistance, like, for example, the temporarily abdication of 'domestic and caretaking duties'.

Although recognition of the benefits that women may derive from traditional customs and practices and the subtle ways in which they may modify and subvert these offers 
important insights into the factors that shape the lives of women in traditional communities, from a feminist perspective her account of agency is none the less troubling. As Deveaux's comparison between women's indirect strategies and the tools employed by peasants against their masters suggests, transgression, subversion and indirect resistance are typically the tactics of the powerless and tend only to have a limited impact. While it may well be true that 'much of what individuals in general want in life comes in ... "mixed bundles”, that require resignation to certain tradeoffs as a means to secure goods one values' (Narayan 2002:422), some bundles are more attractive than others. Although indirect resistance, transgression and subversion may well enable women to transform some aspects of women's traditional social roles, they are unlikely to alter the overarching power relations within the community. The limited range of life options in traditional cultures is liable to leave women with little room, short of outright exit, to negotiate the overall shape of the 'mixed bundles' that constitute their social role. In this context Deveaux is too quick to dismiss the dangers of adaptive preferences. According to Deveaux (2006:93)' in liberal democracies worries about adaptive preferences have less purchase, since 'the majority culture offers a range of life options for women, and few groups are so isolated that their members cannot imagine other possible lives'. This, however, not only underestimates the costs of exit facing women dissatisfied with their traditional roles, it also assumes that such women will have the confidence and skills to avail themselves of the options offered by mainstream society. At the very least this would require an education system that ensures that all children are taught a broad range of skills and that fosters cross-cultural contact. Yet, Deveaux is critical of liberal conceptions of autonomy that entail the rejection of religious schooling that reinforces traditional sexual roles. ${ }^{11}$ Taken together these worries raise real doubts about 
whether the informal democratic activities and general background conditions envisaged by Deveaux will be sufficient to ensure that women will be able to participate on equal terms in formal democratic deliberation governed by a more minimal reading of her conditions for democratic participation. Ultimately Deveaux does not resolve the tensions between her desire to provide a purely procedural account of democratic deliberation that respects participants' actual choices, values and cultural attachments, and her commitment to empowering women to challenge established power relations within both the formal political realm and the wider social and cultural sphere. While her formal definition of the conditions for democratic participation is so demanding that it is difficult to envisage that such deliberation could generate anything other than overwhelmingly liberal outcomes, her endorsement of the South Africa case together with her account of agency point to a reading of the conditions for democratic participation that is so minimal it risks undermining the central goals of her feminist project.

\section{Democracy and Agency}

The difficulties inherent in Deveaux’s response suggest that feminists attracted to the democratisation strategy as a way of reconceptualising the public sphere will need to be more aware of the complex interaction between the capacity for agency in the wider social and personal sphere and the conditions for effective citizenship in the public realm. Ironically, in this effort feminists may benefit from drawing on the recent work of liberal writers such as Habermas. As Habermas (1996) notes, while citizens will only be able to safeguard the life context within which individuals have formulated their identity if they are able to participate in the formulation of the rights 
and norms that govern their life, effective citizenship also requires the protection of individual rights and liberties to ensure that all citizens enjoy a sufficient degree of independence. While Habermas' own model remains too firmly wedded to liberal preoccupations with individual autonomy and impartiality to respond directly to feminist concerns, his work points towards a reconceptualisation of the scope of the public realm and its relationship to the private which neither privileges agency nor participation. ${ }^{12}$ While a purely procedural account of democratic participation is well placed to ensure that cultural minorities are able to bring their values and norms to bear in public deliberation, it can only secure effective citizenship for vulnerable group members such as women if their capacity for agency in the wider social and personal sphere is properly safeguarded. Although Deveaux is correct to highlight the dangers of conceiving of agency in terms of liberal values such as personal autonomy, the difficulties inherent in her conception of agency point to the need for a more robust account that not only safeguards women's basic rights and civil liberties, but also addresses some of the most serious structural inequalities that confront women. In this regard writers such as Nussbaum (1999b) quite rightly point to factors such as economic independence and education as important goals for women. While Deveaux (2006) acknowledges that a commitment to equal political participation may well require state intervention to address structural inequalities such as economic deprivation and lack of education, she fails to recognise the implications of such intervention for the scope of democratic deliberation. For example, a commitment to secure for women a minimal level of economic well-being may well imply that rules regarding inheritance and divorce cannot simply be left to minority groups to negotiate in the process of democratic deliberation. While a liberal state committed to equal citizenship may be able to permit a degree of diversity in this regard, it must set 
a clear framework for minimal provisions. Similarly a regard for women's agency will set real limits to negotiations regarding educational provisions. As noted earlier, if women are to enjoy a realistic right of exit the state has to ensure that they are able to acquire in the course of their education a broad range of skills that extend beyond those required for traditional gender roles. As these examples indicate, even a modest commitment to minimise the most glaring structural inequalities would set significant limits to the type of issues that could be settled by democratic deliberation alone. Given that debates about gender equality and cultural justice typically arise when minorities seek specific exemptions from majority provisions or want community based norms recognised in particular spheres, the nature and content of a framework of minimal provisions that delimit the scope of democratic deliberation is best established on an issue by issue basis. While fundamental individual rights and liberties provide a reference point for determining what constitutes an acceptable minimal standard in such instances, the interpretation and application of these rights varies across liberal polities and liberal democracies will need to draw on the norms of distributive justice and equality provisions that prevail in their particular polity. ${ }^{13}$ Consequently, the precise content of minimal provisions is liable to vary in accordance with the wider political context within which specific debates take place.

While such a minimal framework would secure for women a degree of independence, it does, of course, fall well short of the rather demanding conditions for democratic participation implicit in Okin's substantive reading of Deveaux or Nussbaum's expansive public sphere. A framework of baseline provisions limits rather than eliminates extrapolitical influences and leaves considerable scope for disagreements regarding the role of women in society. While a framework designed to alleviate gross structural inequalities sets limits to the scope of democratic deliberation, within 
these limits such an approach is compatible with a purely procedural account of democratic deliberation. Indeed, within a framework that secures a degree of economic independence for women, informal debate and indirect resistance, transgression and subversion may well be sufficient to ensure that women can protect their interests in formal political deliberations governed by a minimal reading of the conditions for democratic participation.

\section{Conclusion}

While the problems regarding false universalism that continue to beset strategies such as Nussbaum's expansive conception of the public realm may well lead feminists to favour the democratisation approach to the reconceptualisation of the liberal public realm, the problems inherent in Deveaux's account highlight the need for a robust account of agency that secures for women the independence essential for effective participation in both formal and informal democratic deliberation. Yet the preoccupation with self-determination, capacities for self-definition, or authenticity that has characterised recent feminist discourses regarding agency obscures many of the factors that shape the lives of women in tradition communities. Rather than home in on such distinctly liberal values, feminists may be best advised to focus on structural inequalities such as economic deprivation and lack of education. While such an approach sets clear limits to the scope of democratic deliberation, it avoids the difficulties associated with both Nussbaum's expansive conception of the public realm and a substantive reading of Deveaux's conditions for democratic participation. Indeed a framework of baseline provisions designed to secure a degree of economic independence for women may well be sufficient to ensure that women can protect 
their interests in formal political deliberations governed by a minimal reading of the

conditions for democratic participation.

\section{Endnotes}

${ }^{1}$ For a critique of this approach see Mackenzie, 2007.

${ }^{2}$ For instance, while practices such as veiling may represent a symbol of female subservience, some Muslim women have argued that veiling can constitute an empowering practice creating a space for women within the public domain free from the pressures of sexuality, whereas others have come to regard it as an important symbol in their struggle against anti-colonialism. For a more detailed discussion see Honig 1999 and Carens 2000. Similarly, in South Africa studies of attitudes towards lobola , or bride price, suggest that even among women there is considerable support for the practice based on the perception that it 'has positive effects for women, making them feel valued and respected' (C. Walker 1992: 58). Even when women are critical of established cultural practices, their responses are often complex and multifaceted. While the women of the Sufi Pirzada community in Narayan's (2002) study were critical of purda and veiling, they none the less recognised that these practices bring with them certain benefits that they have good reason to value.

${ }^{3}$ Not only were women historically identified with the private sphere of the particular and the affective and thus seen as lacking in the qualities required for public life, if particularity is assigned to the nonpolitical private sphere then once women enter the 'male' public sphere the way in which they differ from men is seen as deviating from the norm. Thus equality becomes defined in terms of the removal of women's disadvantage or disability, with disadvantage being determined by a model that is intrinsically male (Mendus, 1992).

${ }^{4}$ For a full account of Nussbaum's central human functional capabilities see Sex and Social Justice pp 41-42. In this abbreviated account I have drawn upon Charleswoth's (2000) summary of Nussbaum’s capabilities approach..

${ }^{5}$ For Nussbaum this includes all the core capabilities identified in Sex and Social Justice as essential for full human functioning.

${ }^{6}$ For an overview of these debates see for example Dietz (2003).

${ }^{7}$ See for example C. Pateman, (1988) and C. Gilligan (1995).

${ }^{8}$ As Norton (2001) notes, while Nussbaum relates the stories of typically poor and uneducated women in a manner and context that support her own contentions, she does not acknowledge the work of the many women scholars in South Asia, Africa and the Middle East who write on sex and social justice.

${ }^{9}$ For a detailed discussion of these cases see A. Shachar (2001)..

10 Deveaux (2006:223) acknowledges that the conditions for democratic participation may be particularly burdensome for religious communities, 'since nondemocratic forms of decision-making and authority are often constitutive of their identity'. However, she (2006:223) insists that even in these cases the liberal state should encourage the development of democratic means of settling disputes and should 'support internal group processes for the re-evaluation and reform of contested customs and arrangements, particularly for women'.

${ }^{11}$ In this context Deveaux explicitly rejects Marilyn Friedman's (2003) account of procedural autonomy, which insists that women must early in life develop the capacity to reflect upon situations and make decisions.

${ }^{12}$ I addressed the difficulties that surround Habermas' continued pre-occupation with autonomy and impartiality in a previous paper (see Baumeister 2003).

${ }^{13}$ At some level these norms and standards, of course, also reflect democratic processes, in so far as the interpretation and application of individual rights and liberties is the product of mainstream democratic deliberation..

\section{Bibliography}

Arneil, B. (2007), 'Cultural Protections versus cultural justice', in B. Aneil, M. Deveaux, R. Dhamoon and A. Eisenberg (eds.) Sexual Justice/Cultural Justice, London: Routledge., 50-68. 
Baumeister, A. (2003) 'Habermas: Discourse and Cultural Diversity’, Political Studies, Vol.51 (4) 740-758.

Carens, J (2000) Culture, Citizenship and Community, Oxford: Oxford University Press.

Charlesworth, H. (2000), 'Martha Nussbaum’s Feminist Internationalism', Ethics, Vol. 111, October 2000, 64-78.

Deveaux, M. (2005) 'A deliberative approach to conflicts of culture' in Eisenberg, A. and Spinner-Halev, J. (eds.) Minorities within Minorities Equality, Rights and Diversity, Cambridge: Cambridge University Press, 340-62.

Deveaux, M. (2006) Gender and Justice in Multicultural Liberal States, Oxford: Oxford University Press.

Deveaux, M. (2007) ‘Personal autonomy and cultural tradition’ in B. Arneil, M. Deveaux, R. Dhamoon and A. Eisenberg (eds.) Sexual Justice/Cultural Justice, London: Routledge., 139-65.

Dietz, M. G. (2003) 'Current Controversies in Feminist Theory’, Annual Review of Political Science 2003, pp 399-431.

Eissa, D. (1999) 'Constructing the Notion of Male Superiority over Women in Islam', WLUML Occasional Paper 11, November 1999.

Enslin, P. (2003), 'Liberal feminism, diversity and education', Theory and Research in Education’, Vol. 1, No. 1, 2003, 73-87.

Fazaeli, R. (2007) 'Contemporary Iranian Feminism: Identity Rights and Interpretations’ Muslim World Journal of Human Rights, Vol. 4, No. 1, Article 8, pp1 $-24$.

Friedman, M. (2003) Autonomy, Gender, Politics, Oxford: Oxford University Press.

Gilligan, C. (1995) In a Different Voice, Cambridge, MA: Harvard University Press.

Habermas, J. (1996) Between Facts and Norms, Cambridge MA: MIT Press.

Honig, B. (1999) 'My Culture Made Me Do It' in J. Cohem, M. Howard and M.C. Nussbaum (eds.) Is Multiculturalism Bad for Women?, Princeton: Princeton University Press.

Loenen, T., Family law issues in a multicultural setting: abolishing or reaffirming sex as a legally relevant category? A human rights approach. Netherlands Quarterly of Human Rights, 20 (4), 423-443. 
Mackenzie, C. (2007) 'Relational autonomy, sexual justice and cultural pluralism', in B. Arneil, M. Deveaux, R. Dhamoon and A. Eisenberg (eds.) Sexual Justice/Cultural Justice, London: Routledge, 103-21.

Mendus, S. (1992) 'Losing the faith: Feminism and Democracy' in J. Dunn (ed.) Democracy the Unfinished Journey, Oxford: Oxford University Press, 207-19.

Moosa, N. (1995) 'The interim Constitution and Muslim personal law' in S. Liebenberg (ed.), The Constitution of South Africa from a Gender Perspective’, Cape Town: David Philip, 167-84

Narayan, U. (2002) 'Minds of their Own: Choices, Autonomy, Cultural Practices, and Other Women' in L.M. Antony and C.E. Witt (eds.) A Mind Of One’s Own Feminist Essays on Reason and Objectivity, Oxford: West View Press.

Norton, A. (2001) 'Review Essay on Euben, Okin and Nussbaum', Political Theory, Vol. 29, No. 5, 736-49.

Nussbaum, M. (1999a) ‘a Plea for Difficulty’, in Cohen, J., Howard, M. and Nussbaum, M.C. (eds.) Is Multiculturalism Bad for Women? Princeton: Princeton University Press, 105-14.

Nussbaum, M. (1999b) Sex and Social Justice, Oxford: Oxford University Press.

Okin, S. (1994) 'Political Liberalism, Justice and Gender’ Ethics, 105, October 1994, 23-43.

Okin, S. (2005) 'Multiculturalism and feminism: no simple question, no simple answer' in Eisenberg, A. and Spinner-Halev, J. (eds.) Minorities within Minorities Equality, Rights and Diversity, Cambridge: Cambridge University Press, 67-89.

Pateman, C. (1988), 'The Theoretical Subversiveness of Feminism', in C. Pateman and E. Gross (eds.) Feminist Challenges, Sydney: Allen \& Unwin, 1-10.

Phillips, A. (1993) Democracy and Difference, Cambridge: Polity Press.

Shachar, A. (2001) Multicultural Jurisdictions, Cambridge: Cambridge University Press.

Walker, C. (1992) 'Attitudes to lobola: findings from student research projects, Agenda: A Journal about Women and Gender, 13, 57-58.

Young, I.M. (1990) Justice and the Politics of Difference, Princeton: Princeton University Press. 